\title{
Wavelet Packet Transform and Support Vector Machine Based Discrimination of Power Transformer Inrush Current from Internal Fault Currents
}

\author{
Sendilkumar Subramanian (Corresponding author) \\ Department of EEE, St Peters Engineering College Anna University Chennai \\ College Road, Avadi, Tamilnadu, India \\ Tel: 91-44-2655-8080Ｅ-mail:sendilkumar2009@gmail.com \\ Badrilal Mathur \\ Department of EEE, SSN College of Engineering \\ Rajiv Gandhi Salai, Chennai- 603 110, Tamilnadu, India \\ Tel: 91-44-2727-5064 E-mail: mathur1941@yahoo.co.in \\ Joseph Henry \\ Department of EEE, Veltech Engineering College \\ Chennai- 603 110, Tamilnadu, India \\ Tel: 91-44-2684-1601_E-mail: joseph_henry@rediffmail.com
}

\begin{abstract}
This paper presents a Wavelet packet transform with entropy features and support vector machine (SVM) based differential protection of power transformer by using internal fault and inrush current. The wavelet packet transform one of the powerful signal-processing tool and it is used to extract the information of differential current from third level using Db 9 mother wavelet. A two cycles of transformer fault current data is processed through wavelet packet transform to obtain wavelet coefficients and then features are extracted by using Shannon entropy principle. Subsequently, the extracted features are applied as inputs to SVM for distinguishing inrush current from internal fault. The application of this method is studied through detailed simulation of different faults on a power transformer using MATLAB/SIMULINK software. The results of the proposed new technique were found to be reliable, fast and accurate in identifying the fault condition.
\end{abstract}

Keywords: Power transformer, Wavelet packet transform, Internal fault, Inrush current, Shannon entropy, Daubechies wavelet (Db9) and support vector machine

\section{Introduction}

Power transformer is important equipment in the power system and its protection scheme is of vital significance to provide continuous power supply ensuring reliable operation. When the power transformer is switched ON the remnant flux in the transformer draws the large current from the source this current is usually ten times that of the full load current (Rahman, M.A and Jeyasurya.B.1988) . It persists only for a very short duration and decays very quickly, but its very high magnitude causes the relay to operate falsely. Hence such inrush current needs to be discriminated from the internal fault to prevent mal operation.

Traditionally, harmonic restraint technique was used to discriminate the inrush current from internal fault using second harmonic component based on the ratio of second harmonic to fundamental component (P. Liu et.al, 1992). However, it has been reported in certain cases, the internal fault may also contain second harmonic component due to current transformer saturation or due to presence of shunt capacitor or due to the distributive capacitance in the long extra high voltage (EHV) transmission line (T.S.Sidhu et. Al, 1992). In addition, new generation power transformer used low amorphous material in the transformer core design that reduces the second harmonic content during inrush current and thus leading to unused of harmonic restraint techniques (Sidhu, T. S and Sachdev, M. S, 1992)

Later, other approaches using neural network and Fuzzy logic have also been used to process the differential 
current. (P. Bastard et.al, 1995 and D.V. Coury, 2005 ) artificial neural network was employed for power transformer protection but these techniques requires large number of training patterns, time and need to be retrained for the use in different power system. A Fuzzy logic technique has been implemented (A.Wiszniewski, B.Kasztenny, 1995) \& M. C. Shin, and J. H. Kim 2003), these approaches are not robust for transient conditions. The complexity of this method is to design new rules for different cases and it is highly dependent on transformer parameter's. These requires an highly improved techniques to study the above foregoing problem by using various signal processing techniques like S-transform, wavelet transform and wavelet combined with neural network.The frequency analysis is an effective and accurate technique to analyze and classify signals with complex characteristic.

In (S.R. Samantaray et.al 2007), a pattern recognition approach based on S-transform was developed for differential protection of power transformer. Moreover, authors have not included external fault and in this study, for differential protection, second harmonic restrain using adaptive linear comparer (ADALINE) was tested

In ( P.L.Mao and R.K.Aggarwal 2000), a wavelet algorithm based on decision logic has been used for transformer differential protection and wavelet algorithm using wavelet energy were proposed to discriminate the inrush current from internal fault using db2 mother wavelet (A.I.Megahed, A. Ramadan, W.El. Mahdy 2008). For most effective transformer protection, differential current signals are processed to wavelet algorithm and wavelet packet algorithm, compared with various other mother wavelet functions (A.Zabardast.et.al 2008 and S.A.Saleh et.al 2005) From the above reported studies (P.L.Mao et.al 2000,A.I. Megahed et.al 2008, A. Zabardast et.al. 2008,

S. A. Saleh. et.al 2005), the variations of detailed coefficients are obtained to distinguish magnetizing inrush and fault. Moreover the discrete wavelet transform breaks only approximation version and also for each resolution it has different frequency band. Hence the frequency information may lost. Alternatively, the WPT provides same frequency band widths in each resolution for recording / analyzing Inrush and fault features under each frequency bands. Meanwhile, working speed is faster than the traditional DWT.

There are several types of mother wavelets available ( S. A. Saleh. et.al 2005) therefore appropriate selection of mother wavelets is essential for specific application.

In this paper, a new algorithm for power transformer protection is proposed based on wavelet packet transform with entropy features and support vector machine to identify magnetizing inrush current, internal fault and normal current. The proposed algorithm has been tested by creating faults on both primary and secondary of the transformer and also on transmission line. The simulation studies of transformer different faults have been carried out using MATLAB/SIMULINK and Wavelet packet transform has been implemented using functions from Wavelet toolbox in MATLAB environment. The SVM technique has also been implemented in MATLAB environment using bioinformatics tool box advantage of the proposed algorithm (WPT) provides more accurate and detailed representation of the decomposed signals. Moreover, WPT are localized in time in offering better signal approximation and decomposition.

\section{Principle of Wavelet packet transform and Feature Extraction}

The structure of wavelet packet transform (WPT) is similar to discrete wavelet transform (DWT). Both have the framework of multi-resolution analysis (MRA). The main difference in the two techniques is the WPT can simultaneously break up detail and approximation versions, but DWT only breaks up an approximation version. Therefore, the WPT have the same frequency bandwidths in each resolution and DWT does not have this property. The mode of decomposition does not increase or lose the information within the original signals. Therefore, the signal with great quantity of middle and high frequency signals can offer superior time-frequency analysis. The WPT suits signal processing especially nonstationary signals because the same frequency bandwidths can provide good resolution regardless of high and low frequencies. The principle of WPT can be described as follows (Jian - Da Wu, Chiu-Hong Liu 2009)

$$
\mathrm{W}^{\mathrm{n}} \mathbf{j}, \mathbf{k}(\mathbf{t})=2^{\mathbf{j} / 2} \mathbf{W}^{\mathbf{n}}\left(2^{\mathbf{j}} \mathbf{t}-\mathbf{k}\right),
$$

Where the integers $\mathbf{j}, \mathbf{k}$ - index scale and translation operations. The index $\mathbf{n}$ is an operation modulation parameter (or) oscillating parameter. The first wavelet packet functions are scaling and mother wavelet functions:

$$
\begin{aligned}
& \mathbf{W}^{0} 0,0(t)=\phi(t), \\
& \mathbf{W}^{1} 0,0(t)=\psi(t),
\end{aligned}
$$

The equation (2) and (3) represents scaling and mother wavelet functions respectively. 
Where $n=2,3 \ldots$ the function can be defined by following recursive relation ship

$$
\begin{aligned}
& \mathbf{W}^{2 \mathbf{n}_{0,0}}(\mathbf{t})=\sqrt{2} \sum_{\mathbf{k}} \mathbf{h}(\mathbf{k}) \mathbf{W}_{1, \mathbf{k}}(2 \mathbf{t}-\mathbf{k}), \\
& \mathbf{W}^{2 \mathbf{n}+1} 0,0(\mathbf{t})=\underset{\mathbf{k}}{\sqrt{2} \sum_{\mathbf{k}} \mathbf{g}(\mathbf{k}) \mathbf{W}_{1}, \mathbf{k}(2 \mathbf{t}-\mathbf{k}),}
\end{aligned}
$$

Where $\mathrm{h}(\mathrm{k})$ and $\mathrm{g}(\mathrm{k})$ are the quadrature mirror filter (QMF) associated with the predefined scaling function and mother wavelet function. The wavelet packet coefficients, $\mathrm{W}_{\mathrm{j}, \mathrm{k}}^{\mathrm{n}}$ are computed by the inner product $<\mathrm{f}(\mathrm{t}), \mathrm{W}_{\mathrm{j}, \mathrm{k}}^{\mathrm{n}}>$ where defined as

$$
W^{\mathbf{n}} \mathbf{j}, \mathbf{k}=<\mathbf{f}(\mathbf{t}) W^{\mathbf{n}} \mathbf{j}, \mathbf{k}>=\int \mathbf{f}(\mathbf{t}) \mathbf{W}^{\mathbf{n}} \mathbf{j}, \mathbf{k}(\mathbf{t}) \mathbf{d t} \text {. }
$$

The framework of WPT algorithm broken up to three resolution levels is shown in the Figure.1 In this present study, the transformer fault cases will be broken up to third resolution. WPT framework is broken up to third resolution levels $\mathrm{j}=3$, As a result, three resolutions will produces 8 subspaces $\left(2^{\mathrm{j}}=2^{3}=8\right)$ and wavelet frequency intervals of each subspace can be computed by

$$
\left((\mathbf{n}-1) 2^{-\mathbf{j}-1} \mathbf{f}_{\mathbf{S}}, \mathbf{n} 2^{-\mathbf{j}-1} \mathbf{f}_{\mathbf{s}}\right), \mathbf{n}=1,2,3,4 \ldots .8,
$$

where $\mathrm{fs}$ is the sampling frequency. In this study fs $=10 \mathrm{kHz}$. X(n) is the original signal with the frequency $\left[0.2^{-1}\right.$ $\mathrm{f}_{\mathrm{s}}$ ]. The frequency interval of $1^{\mathrm{st}}$ and last node in the $3 \mathrm{rd}$ resolution is given by [0-1250 hz] and [ $8750-10 \mathrm{Khz}$ ] as given in Table.1 respectively.

\subsection{Choice of mother wavelet}

There are different types of mother wavelets available in the literature such as Haar, Daubiechie (Db), Coiflet(coif), symmetry(sym) etc. The selection of mother wavelet plays a major role in the characterization of signal under consideration. It has been reported by several authors using Db mother wavelet has perfect choice for various power system applications like transmission line protection (Sami Ekici et.al 2008), Harmonic detection (Tuntisak.S .et.al 2007) Bus bar Protection ( Mohammed. M.E.et.al 2005) ,Power quality (Guo-sheng Hu et.al 2007) and Partial discharge (J. Jin et.al 2006)

\subsection{Feature Extraction Using Shannon Entropy}

Entropy is a measure of uncertainty that is used in various fault conditions after the signal processing of the original signal by using WPT (Jian - Da Wu, Chiu-Hong Liu 2009). To reduce data set insize, wavelet entropy is applied to wavelet coefficients. The wavelet entropy is the sum of square of detailed wavelet transform coefficients. The entropy of wavelet coefficients is varying over different scales dependent on the Input signals. This wavelet entropy of coefficients can be defined as.

$$
\mathbf{E n}=\sum_{\mathbf{n}=1}^{8} \log \left(\mathrm{W}_{\mathrm{j}} \mathrm{n}, \mathrm{k}\right)^{2}
$$

Where $\mathrm{W}^{\mathrm{n}} \mathrm{j}, \mathrm{k}$ is the coefficients of the subspace after wavelet packet decomposition and $\mathrm{n}=0,1,2 . .8$

\section{Support Vector Machine}

SVM is a relatively new computational learning method based on the statistical learning theory. In SVM, the original input space is mapped into a high-dimensional dot product space called a feature space, and in the feature space, the optimal hyper plane is determined to maximize the generalization ability of the classifier. The optimal hyper plane is found by exploiting the optimization theory, and respecting insights provided by the statistical learning theory.

SVMs have the potential to handle very large feature spaces, because the training of SVM is carried out so that the dimension of classified vectors does not have as a distinct influence on the performance of SVM as it has on the performance of conventional classifiers. That is why it is noticed to be especially efficient in large classification problems. This will also benefit in fault classification, because the number of features to be the basis of fault diagnosis may not have to be limited. Also, SVM-based classifiers are claimed to have good generalization properties compared to conventional classifiers, because in training the SVM classifier, the so-called structural misclassification risk is to be minimized, whereas traditional classifiers are usually trained so that the empirical risk is minimized. SVM is compared to the radial basis function (RBF) neural network in an industrial fault classification task, and it has been found to give better generalization. SVMs may have problems 
with large data sets, but in the development of fault classification routines, these are usually not even available (Dash et.al 2007).

Let $\mathrm{n}$-dimensional input $\mathrm{Xi}(\mathrm{i}=1,2, \ldots \mathrm{M}), \quad \mathrm{M}$ is the number of samples belong to class-I or Class-II, and associated labels be $\mathrm{Yi}=1$ for Class I and $\mathrm{Yi}=-1$ for class $-\mathrm{II}$, respectively. For linearly separable data a hyperplane $\mathrm{f}(\mathrm{x})=0$ which separates the data can determined

$$
\mathbf{f}(\mathbf{x})=\mathbf{w}^{\mathbf{T}} \mathbf{x}+\mathbf{b}=\sum_{\mathbf{j}=1}^{\mathbf{n}} \mathbf{w}_{\mathbf{j}} \mathbf{x} \mathbf{j}+\mathbf{b}=0
$$

Where " $w$ " is an dimensional vector and " $b$ " is a scalar. The vector " $w$ "and the scalar " $b$ " determine the position of the separating hyperplane. This separating hyperplane satisfies the constraints

$F\left(x_{i}\right) \geq 1$ if $y_{i}=1$ and $f\left(x_{i}\right) \geq-1$ if $y_{i}=-1$ and this results in

$y_{i} f\left(x_{i}\right)=y_{i}\left(w^{T} \quad x_{i}+b\right) \geq+1$ for $i=1,2, \ldots . . M$

The separating hyperplane that creates the maximum distance between the plane and the nearest data is called the optimal separating hyperplane as shown in the Figure.2. The geometrical margin is found to be $\|\mathbf{w}\|^{-2}$ (Dash et.al 2007).

Taking into account the noise with slack variables $\xi_{\mathbf{i}}$ and error penalty $\mathrm{C}$, the optimal hyper plane can be found by solving the following convex quadratic optimization problem:

minimize

$\frac{1}{2}\|\mathbf{w}\|^{2}+\mathbf{C} \sum_{\mathbf{i}=1}^{\mathbf{M}} \xi_{\mathbf{i}}$

subject to

$$
\mathbf{y}_{\mathbf{i}}\left(\mathbf{w}^{\mathbf{T}} \mathbf{x}_{\mathbf{i}}+\mathbf{b}\right) \geq 1-\xi_{\mathbf{i}} \text { for } \mathrm{i}=1,2, \ldots \mathrm{M}
$$

$\xi_{\mathbf{i}} \geq 0$ for all i

where $\xi_{\mathrm{i}}$ is measuring the distance between the margin and the examples $\mathrm{x}_{\mathrm{i}}$ lying on the wrong side of the margin. The calculations can be simplified by converting the problem with Kuhn-Tucker conditions into the equivalent Lagrange dual problem, which will be

maximize

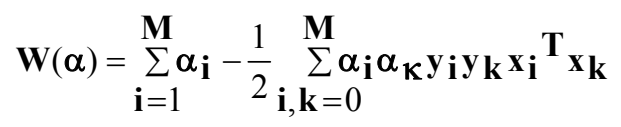

subject to

$$
\sum_{\mathbf{i}=1}^{\mathbf{M}} \mathbf{y}_{\mathbf{i}} \boldsymbol{\alpha}_{\mathbf{i}}=0, \mathrm{C} \geq \alpha_{\mathrm{i}} \geq 0, \mathrm{i}=1,2, \ldots . \mathrm{M}
$$

The number of variables of the dual problem is the number of training data. Let us denote the optimal solution of the dual problem with $\alpha^{*}$ and $\mathrm{W}^{*}$ the equality conditions in (9) holds for the training input -output pair(xi, yi) only if the associated $\alpha^{*} \neq 0$.In this case, training examples xi is a support vector (SV).The number of SVs is considerably lower than the number of training samples making SVM computationally very efficient (Dash et.al 2007)

The value of the optimal bias $b *$ is found from the geometry,

$$
\mathbf{b}^{*}=-\frac{1}{2} \sum_{\mathbf{S V s}} \mathbf{y}_{\mathbf{i}} \alpha_{\mathbf{i}}^{*}\left(\mathbf{S}_{1}^{\mathbf{T}} \chi_{\mathbf{i}}+\mathbf{S}_{2}^{\mathbf{T}} \chi_{\mathbf{i}}\right)
$$

Where S1 and S2 are the arbitrary SVs for class-1 and class-2, respectively. Only the samples associated with SVs are summed because the other elements of the optimal Lagrange multiplier $\alpha^{*}$ are equal to zero. The final decision function is given by

$$
\mathbf{f}(\mathbf{x})=\sum_{\mathbf{S V s}} \alpha_{\mathbf{i}} \mathbf{y}_{\mathbf{i}} \chi_{\mathbf{i}}^{\mathbf{T}} \chi+\mathbf{b}^{*}
$$


The unknown data sample $\mathrm{x}$ is then classified as,

$\chi=\epsilon\left\{\begin{array}{l}\text { Class }-1, \text { if } \mathrm{f}(\mathrm{x}) \geq 0 \\ \text { Class }-2, \text { otherwise }\end{array}\right.$

The nonlinear classification problems can also be solved by using SVM applying a kernel function. The classified data is mapped onto a high-dimensional feature space where the linear classification is possible. Using nonlinear vector function,

$$
\phi(\chi)=\phi_{1}(\chi), \phi_{2}(\chi), \ldots \ldots, \phi_{\mathbf{m}}(\chi), \quad \mathrm{m}>>\mathrm{n}
$$

to map the $\mathrm{n}$-dimensional input vector $\mathrm{x}$ into the $\mathrm{m}$-dimensional feature space, the linear decision function in dual form is given by,

$$
\mathbf{f}(\chi)=\sum_{\mathbf{S V s}} \alpha_{\mathbf{i}} \mathbf{y}_{\mathbf{i}} \phi^{\mathbf{T}}\left(\chi_{\mathbf{i}}\right) \phi(\chi)
$$

Notice that in (18) as well as (11), the inner products are used. A function that returns a dot product of the feature space mapping of the original data points is called a kernel function $K(X, Z)=\Phi^{\mathrm{T}}(\chi) \Phi(\chi)$.

The learning in the feature space does not re- quire the inner products where a kernel function is applied. Using a kernel function, the decision function can be written as,

$$
\mathbf{f}(\mathbf{X})=\sum_{\mathbf{S V s}} \alpha_{\mathbf{i}} \mathbf{y}_{\mathbf{i}} \mathbf{K}\left(\chi_{\mathbf{i}}, \chi\right)
$$

There are different kernel functions used in the literature. Mercer's theorem states that any symmetric positive-definite matrix can be regard as a kernel matrix. In this paper, Gaussian radial basis kernel function, which gives the best results, is selected. The radial basis kernel function is defined as,

$$
\mathbf{K}(\chi, \mathbf{Z})=\exp =\left(--\frac{\|\chi-Z\|^{2}}{2 \sigma^{2}}-\right)
$$

Where $\sigma$ is the width of the Gaussian function. The detailed information about the SVM can be found in Vapnik (1998) and Vojtechand Hlavac (2004)

\section{Fault Classification Using Wavelet Packet Transform and Support Vector Machine}

The new method of identifying Inrush current from internal fault is obtained from wavelet packet transform using entropy principle and SVM.Figure. 3 shows the procedure for fault classification, and it follows:

- $\quad$ Obtain the samples of differential current signals at $20 \mathrm{kHz}$ sampling frequency from current transformers

- $\quad$ Applying the wavelet packet algorithm for differential current signals and decomposed to $3^{\text {rd }}$ level and down sample the signal by two at each level to avoid over crowding of samples.

- $\quad$ Applying Shannon entropy principle and calculate the sum entropy principle from each node at $3^{\text {rd }}$ level and their frequency information are depicted in Table.1

- $\quad$ For effective and accurate discrimination of Inrush current and internal faults a Shannon entropy principle is used for feature vectors obtained from Node 3. Later these feature vectors are processed through SVM for fault classification

- $\quad$ Assigned target has No fault for Feature vectors of Inrush, external fault and normal current and target assigned has Fault for internal Fault.

\section{System studied}

In order to investigate the applicability of the proposed algorithm, a detailed simulation study has been carried out on power system model shown in the Figure.4 The source is simulated by an equivalent $50 \mathrm{~Hz} 450 \mathrm{MVA}$ Synchronous machines with 500 MVA transformer and $100 \mathrm{MW}$ load is connected in parallel. A (500/230) kV star to delta connected transformer is employed with its neutral grounded. The CT's used in the primary side is delta connected and star connected in the secondary side. The saturation of core have also been considered. The relay unit is connected to the CT's on both HV and LV sides of the transformer. The a sampling rate of $20 \mathrm{kHz}$ is considered. The cycle contains 800 samples per power frequency band at $50 \mathrm{~Hz}$. The generator $\mathrm{X} / \mathrm{R}$ ratio is 10 . The primary winding voltage $\mathrm{R}(\mathrm{pu})$ and $\mathrm{L}(\mathrm{pu})$ are $500 \mathrm{kV} .0 .0078$ and 0.259 , respectively, and secondary winding voltage is $\mathrm{R}(\mathrm{pu})$ and $\mathrm{L}(\mathrm{pu})$ are $230 \mathrm{k} . \mathrm{V} 0.0078$ and 0.259 respectively. The simulation model are developed using 
Matlab-Simulink software modules. The load taken here is $100 \mathrm{MW}$ and 80 MVAR.

\section{Results and discussions}

\subsection{Transformer Fault Signal Analysis Using Wavelet Packet Transform}

\subsubsection{Inrush Currents}

Figure.5 shows a typical magnetizing inrush current waveforms of level 3, which corresponds to Phase a, Phase $\mathrm{b}$ and Phase $\mathrm{c}$ of three phase differential currents from Current transformer secondary side. The differential current harmonics should not affect the relay performance, Since fault current waveforms are distorted, its extracted features are decomposed to level 3 using Wavelet packet Transform. In this study a 800 samples per frequency band is processed through wavelet packet algorithm and using Shannon entropy, the maximum entropy values are retrieved to obtain series of wavelet coefficients for inrush current, and its corresponding maximum entropy values are tabulated in Table. 2 and Table. 3 The maximum entropy values are obtained from inrush current is found to be very less when compared to Internal fault current at level 3 . For the other cases like external faults also entropy values are found to be very less when compared to the threshold value and the relay should not operate for the external fault case in the real time.

\subsubsection{Internal Faults}

If the transformer internal fault occurs in primary or secondary sides, the magnitude of current in that corresponding faulted phase changes and differential protection technique is used to sample the differential current Iad, Ibd and Icd from Current transformers. Figure.6 shows the typical internal fault current and amplitude of wavelet coefficients at $3^{\text {rd }}$ level and reveals more information such as time domain constituent part at the frequency band. It can be seen form Figure. 6 the fault current information is very rich during internal fault. In this study a 800 samples of fault current and $20 \mathrm{kHz}$ sampling frequency is considered and processed through WPT to obtain the series of wavelet coefficients, signals were decomposed to level 3 and the frequency information obtained at $3^{\text {rd }}$ level has been shown in Table.1. The proposed technique is based on extracted features from differential current signals during internal fault. Next using Shannon entropy principle, the decomposed wavelet coefficients are squared and maximum entropy values were obtained at $3^{\text {rd }}$ level and can be used for identifying internal fault from inrush current. From Table. 2 and 3, the entropy values for internal fault current are found to be greater than inrush current and the trip signal has been issued based on the maximum wavelet coefficients from the fault inception and it can be set as threshold value and for accurate discrimination task these maximum entropy values and $\mathrm{H}(3,0)$ are used as inputs to SVM for fault classification. Totally 264 cases are simulated (includes training and testing) and has been shown in the Table.4.

\section{Implementation of SVM (Linear kernel function)}

The transformer different cases like Inrush current, internal fault and External fault are simulated. A 800 sample /cycle of data is taken for analysis. At first stage differential harmonic current is extracted from the current transformers and transformed to time-frequency domain using wavelet packet transform. The entropy distribution of the detailed coefficients and approximate of the fault current waveforms form the feature vectors. The Feature vectors are H $(3,0),(3,1),(3,2),(3,3),(3,4),(3,5),(3,6),(3,7)$, are obtained from the $3^{\text {rd }}$ level of decomposition for the corresponding signals. Next using Shannon entropy principle Features are extracted. A total of 264 feature vectors are used for training and testing to perform transformer fault classification.

The input patterns processed through SVM contains data sets of 132 × 2 of $\mathrm{H}(3,0)$ and Maximum entropy are processed through SVM for training and remaining $132 \times 2$ for testing. The inputs applied to SVM is wavelet packet coefficients obtained from $\mathrm{H}(3,0)$ and maximum entropies obtained from $3^{\text {rd }}$ level. The target is assigned has No Fault for (Inrush current, Normal current and External fault) if maximum entropy value is less than 2000 and if maximum entropy values greater than 2000 has been shown in the Figure.7 and 8 . Target assigned as fault for internal faults. As SVM consists of two inputs. First input is from Node $\mathrm{H}(3,0)$ and second is from maximum entropy values. Over all accuracy is found to be $99.24 \%$ is obtained through 264 feature vectors.

\section{Conclusion}

WPT using entropy features and SVM based algorithm are used to discriminate power transformer inrush current and internal fault current is presented in this paper. The output of current transformer is inrush or internal fault current are decomposed to $3^{\text {rd }}$ level. Using Shannon entropy principle the entropy at $3^{\text {rd }}$ level is obtained and used has inputs to SVM to discriminate the inrush current and internal fault. The proposed method is based on amplitudes of sum entropies at the resolution level 3 of $\mathrm{H}(3,0)$ to $\mathrm{H}(3,7)$. The ability of the new method has been demonstrated by simulating various cases on a typical power system. The test results confirm the effectiveness of the proposed algorithm 


\section{References}

A.I.Megahed, A. Ramadan, W.El. Mahdy. (2008). Power transformer differential relay using wavelet transform energies, in: Power and Energy Society General Meeting , IEEE, 20-24,1- 6.

A.Wiszniewski, B.Kasztenny. (1995). A multi-criteria differential transformer relay based on fuzzy logic, IEEE Trans. Power Deliv, Vol.10, no .4, 1786-1792.

A.Zabardast, M.R.Feyzi and A.Mehraein. (2008). Distinction between Inrush current of Power Transformer an fault Currents in differential protection using wavelet transformer, in: Proceedings of IEEE International Conference on Electric Utility Deregulation and Restructuring and Power Technologies, 1-6, 2008.

D.V.Coury and E.C.Segatto. (2005). An alternative approach using artificial neural networks for power transformer protection, European Trans. On Electric. Power Vol.16, no. 1, 63-67.

Guo-sheng Hu, Feng-Feng Zhu,ZhenReb. (2007). Power quality disturbance identification using WPT entropy and weighted SVM, Expert system with applications, Vol.35, (2), 143 - 149.

J. Jin, C.S. Chang, C. Chang, T. Hoshino, M. Hanai and N. Kobayashi. (2006). Classification of partial discharge events in gas insulated substations using wavelet packet transform and neural network approaches IEE Proc.-Sci. Meas. Technol., Vol. 153, No. 2, 55-63.

Jian-Da Wu,Chiu-Hong Liu. (2009). 'An expert system for fault diagnosis in internal combustion engines using WPT and NN', Expert systems with applications Vol. 36 no. (3), 4278-4286

M. C. Shin, and J. H. Kim. (2003). Fuzzy logic-based for large power transformer protection, IEEE Trans. Power Del., vol. 18 , no. 3, 718-713.

Mohammed.,M.E. (2005). High speed differential bus bar protection using WPT', IEEE Proc-Generation-Transmission. Distribution, Vol.152, no. (6), 927- 933.

P. Bastard, M. Meunier, and H. Regal(1995 ) Neural network based algorithm for power transformer differential relays, IEE Proc. Inst. Elect. Eng. Vol.142, no.4, 386-392.

P.L.Mao and R.K.Aggarwal. (2000). A wavelet transform based decision making logic method for discrimination between internal faults and inrush currents in power transformers, International journal of Electric power and Energy systems, Vol..22, no.6, 389-395.

P.Liu,O. P. Malik, C. Chen, G. S. Hope, and Y. Guo. (1992). Improved operation of differential protection of power transformers for internal faults”, IEEE Transactions On Power Delivery Vol.7,no. 4,1912-1919

Rahman,M.A and Jeyasurya,B. (1988). A state-of-the-art review of transformer protection algorithms, IEEE Trans. Power Del., vol. 3, No. 2,534-544.

S.A.Saleh and M. A.Rahman. (2005). Modeling and protection of a three phase power transformer using wavelet packet transform, IEEE Transactions On Power Delivery, Vol. 20,no. 2,pp. 1273-1282.

S.R. Samantaray, B.K. Panigrahi, P.K. Dash and G. Panda. (2007). Power transformer protection using S-transform with complex window and pattern recognition approach, IET Gen., Trans., Dist., Vol.1 no.2 278-286.

Sami Ekici, Selcuk Yildirim and Mustafa Poyraz. (2008). Energy and entropy-based feature extraction for locating fault on transmission lines by using neural network and wavelet packet decomposition Expert Systems with Applications Vol. 34 no. 4 2937-2944

Sidhu, T. S and Sachdev, M. S. (1992). On line identification of magnetizing inrush and internal faults in three phase transformers', IEEE Trans.Power Del., Vol. 7, no. 4, ,1885-1890.

T.S.Sidhu,M.S.Sachdev,H.C.Wood and M.Nagpal. (1992). Design, implementation and testing of a micro-processor-based high-speed relay for detecting transformer winding faults", IEEE Trans. Power Delivery Vol. 7, no.1,108-117.

Tuntisak.S and Premrudeepreechacharn.S. (2007). Harmonic Detection in Distribution Systems Using Wavelet Transform and Support Vector Machine Proceedings of 2007 IEEE Lausanne Power tech, July (1-5), 1540 1545.

Vapnik, V. (1998). The support vector method of function estimation. In J. Suykens \&Vandewalle (Eds.), Nonlinear modeling: Advanced black-box techniques. Kluwer Academic Publishers.

Vojtech, F., \& Hlavac, V. (2004). Statistical pattern recognition toolbox for MATLAB. SPRTOOL User's Guide. 
Table 1. Characteristic of Wavelet Packet Transform

\begin{tabular}{|l|c|l|l|l|l|l|l|l|}
\hline $\begin{array}{l}\text { Nodes at } \\
\text { Third Level }\end{array}$ & $\begin{array}{c}\text { Node } \\
(3,0)\end{array}$ & $\begin{array}{l}\text { Node } \\
(3,1)\end{array}$ & $\begin{array}{c}\text { Node } \\
(3,2)\end{array}$ & $\begin{array}{c}\text { Node } \\
(3,3)\end{array}$ & $\begin{array}{c}\text { Node } \\
(3,4)\end{array}$ & $\begin{array}{c}\text { Node } \\
(3,5)\end{array}$ & $\begin{array}{c}\text { Node } \\
(3,6)\end{array}$ & $\begin{array}{c}\text { Node } \\
(3,7)\end{array}$ \\
\hline Frequency $(\mathrm{Hz})$ & $0-1250$ & $1250-2500$ & $2500-3750$ & $3750-5000$ & $5000-6250$ & $6250-7500$ & $7500-8750$ & $8750-10000$ \\
\hline
\end{tabular}

Table. 2. (Entropy values at node 3 for with out load)

\begin{tabular}{|c|c|c|c|c|c|c|c|c|c|c|c|}
\hline \multicolumn{2}{|c|}{$\begin{array}{l}\text { Fault types } \\
\text { inrushinormal }\end{array}$} & $\mathrm{H}(30)$ & $H(31)$ & $\mathrm{H}(32)$ & $\mathrm{H}(33)$ & $\mathrm{H}(34)$ & $\mathrm{H}(35)$ & $\mathrm{H}(36)$ & $\mathrm{H}(37)$ & $\begin{array}{l}\text { Max } \\
\text { (H(sum)) }\end{array}$ & $\begin{array}{l}H \text { (net } \\
\text { sum) }\end{array}$ \\
\hline \multirow{3}{*}{ NORMAL } & Phase A & 0.2732 & 0.0015 & 0.2758 & 0.0049 & $6.9365 \mathrm{e}-06$ & $3.3900 \mathrm{e}-06$ & $2.2627 e-06$ & $7.4173 e-06$ & 0.5555 & \multirow{3}{*}{1.6200} \\
\hline & Phase B & 0.2721 & 0.0046 & 0.2832 & 0.0112 & $7.7253 \mathrm{e}-06$ & $4.2231 \mathrm{e}-06$ & $2.1993 \varepsilon-06$ & $9.9826 \mathrm{e}-06$ & 0.5711 & \\
\hline & Phase C & 0.2530 & 0.0032 & 0.2305 & 0,0068 & $9.3313 e-07$ & $7.5574 \mathrm{e}-07$ & $4.5355 e-07$ & $2.070 \mathrm{le}-06$ & 0.4934 & \\
\hline \multirow{3}{*}{ INRUSH } & Phase A & 159.226 & 0.1405 & 340.3429 & 1.1594 & $2.1926 \mathrm{c}-04$ & $1.8071 \mathrm{le}-04$ & $1.6717 e-04$ & $1.6802 e-04$ & 500.8701 & \multirow{3}{*}{1084.8} \\
\hline & Phase B & 7.3446 & 0.1562 & 9.5487 & 1,0993 & $1.3308 \mathrm{e}-04$ & $1.0109 \mathrm{e}-04$ & $1.5978 \mathrm{e}-04$ & $1.4311 \mathrm{e}-04$ & 18.1492 & \\
\hline & Phase C & 180.712 & 0.1448 & 383.7981 & 1.0989 & $2.1326 \mathrm{e}-0.4$ & $1.7981 \mathrm{e}-04$ & $2.3907 e-04$ & $1.7851 \mathrm{e}-04$ & 565,7548 & \\
\hline \multirow{3}{*}{$\begin{array}{l}\text { EXTERN } \\
\text { AL FAULT }\end{array}$} & Phase A & 0.0783 & $1.6992 e-005$ & 0.0742 & $1.0900 k-04$ & $7.6579 \mathrm{e}-09$ & $1.5429 \mathrm{e}-09$ & $1.2487 e-08$ & $6.2855 \mathrm{e}-09$ & 0.1526 & \multirow{3}{*}{0.4834} \\
\hline & Phase B & 0.0821 & $2.4132 \mathrm{e}-006$ & 0.0872 & $1.2803 e-05$ & $1.5115 \mathrm{e}-09$ & $2.8972 \mathrm{e}-10$ & $2.4227 e-09$ & $1.2093 \mathrm{e}-09$ & 0.1693 & \\
\hline & Phase C & 0,0809 & $7.5699 \mathrm{e}-006$ & 0.0806 & $7.5345 c-05$ & $2.6244 c-09$ & $5.4259 \mathrm{e}-10$ & $4.3283 c-09$ & $2.1857 \mathrm{e}-09$ & 0.1615 & \\
\hline \multirow{3}{*}{$A G$} & Phase A & 6926.2 & 0.0935 & 10888 & 0.8804 & $6.3603 e-05$ & $3.2565 \mathrm{e}-05$ & $6.4570 \mathrm{e}-05$ & $6.1145 e-05$ & 17815 & \multirow{3}{*}{$\begin{array}{l}35841 . \\
851\end{array}$} \\
\hline & Phase B & 10.8862 & 0.1172 & 8.0114 & 0.8356 & $1.6765 e-04$ & $1.1836 \mathrm{e}-04$ & $1.3326 e-04$ & $1.5231 \mathrm{e}-04$ & 19.8510 & \\
\hline & Phase C & 7005.8 & 0.0855 & 11000 & 0.9636 & $5.0397 \mathrm{e}-05$ & $2.4523 \mathrm{e}-05$ & $5.1167 e-05$ & $5.1236 \mathrm{e}-05$ & 18007 & \\
\hline \multirow{3}{*}{ BG } & Phase A & 3462.7 & 0.5212 & 4454.9 & 1.6500 & $1.0128 \mathrm{e}-04$ & $7,4686 \mathrm{e}-04$ & $7.4686 e-04$ & $3.3283 e-04$ & 7919.8 & \multirow{3}{*}{$\begin{array}{l}15749 . \\
1435\end{array}$} \\
\hline & Phase B & 3419.5 & 0.4762 & 4399.1 & 1.7088 & $4.1706 \mathrm{e}-04$ & $1.2415 \mathrm{e}-04$ & $6.5789 c-04$ & $4.4600 \mathrm{e}-04$ & 7820.8 & \\
\hline & Phase C & 4.0445 & 0.0923 & 3.9870 & 0.4194 & $1.3197 \mathrm{e}-04$ & $6.986 \mathrm{le}-05$ & $7.8919 c-05$ & $7.8904 \mathrm{c}-05$ & 8.5435 & \\
\hline \multirow{3}{*}{$\mathrm{CG}$} & Phase A & 4.3677 & 0.0671 & 3.5716 & 0.4742 & $5.5407 \mathrm{e}-05$ & $7.4094 e-05$ & $1.2314 c-04$ & $7.4782 \mathrm{e}-05$ & 8.4809 & \multirow{3}{*}{$\begin{array}{l}23240 . \\
4809\end{array}$} \\
\hline & Phase B & 4751.3 & 0.3470 & 6920.3 & 1.4103 & $3,3406 \mathrm{e}-04$ & $8.0356 \mathrm{e}-05$ & $5,4621 e-04$ & $2.8286 \mathrm{e}-04$ & 11673 & \\
\hline & Phase C & 4701.5 & 0.3613 & 6856.1 & 1.2333 & $3.2133 e-04$ & $8.8060 \mathrm{e}-05$ & $5.2933 c-04$ & $2.7788 \mathrm{e}-04$ & 11559 & \\
\hline \multirow{3}{*}{$\mathrm{ABG}$} & Phase A & 10094 & 0.4471 & 14388 & 1.5279 & $3.2718 \mathrm{e}-04$ & $7.1273 \mathrm{e}-05$ & $5.3654 c-04$ & $2.7704 e-04$ & 24484 & \multirow{3}{*}{$\begin{array}{l}49261 . \\
8\end{array}$} \\
\hline & Phase B & 3094.8 & 0.5249 & 3896.8 & 1.5790 & $4.8216 \mathrm{c}-04$ & $1.0858 \mathrm{e}-04$ & $8.0414 c-04$ & $4.1579 \mathrm{c}-04$ & 6993.8 & \\
\hline & Phase C & 6885.1 & 0.0164 & 10899 & 0.3291 & $2.3780 \mathrm{e}-05$ & $5.66+3 \mathrm{e}-06$ & $4,0698 e-05$ & $2.0880 \mathrm{e}-05$ & 17784 & \\
\hline \multirow{3}{*}{$\mathrm{BCG}$} & Phase A & 4599.7 & 0.3773 & 6407.7 & 1.4425 & $2.8503 \mathrm{e}-04$ & $6.5202 \mathrm{e}-05$ & $4.6316 c-04$ & $2.4124 \mathrm{e}-04$ & 11009 & \multirow{3}{*}{41272} \\
\hline & Phase B & 6400,1 & 0.7333 & 7941.1 & 1.7081 & $7.6964 c-04$ & $1.7634 \mathrm{e}-04$ & 0,0013 & $6.6681 \mathrm{le}-0.4$ & 14344 & \\
\hline & Phase C & 6275.3 & 0.1746 & 9643.2 & 0.6896 & $1.7002 \mathrm{e}-04$ & $4.0841 \mathrm{e}-05$ & $2.7671 \mathrm{e}-04$ & $1.4501 \mathrm{e}-04$ & 15919 & \\
\hline \multirow{3}{*}{$\mathrm{CAG}$} & Phase A & 6014.2 & 0.1982 & 9114.7 & 1.1384 & $1.1140 c-04$ & $2.3639 \mathrm{e}-05$ & $1.8119 \mathrm{e}-04$ & $9.3064 \mathrm{e}-05$ & 15130 & \multirow{3}{*}{55491} \\
\hline & Phase B & 3378.8 & 0.4536 & 4514.2 & 1.4875 & $4.2678 \mathrm{c}-0.4$ & $9.7282 \mathrm{e}-05$ & $7.1131 \mathrm{e}-04$ & $3.6888 \mathrm{e}-04$ & 7895 & \\
\hline & Phase C & 12803 & 0.1193 & 19662 & 0.6083 & $1.2918 \mathrm{e}-04$ & $3.0106 \mathrm{e}-05$ & $2.1859 c-04$ & $1.1298 \mathrm{e}-04$ & 32466 & \\
\hline \multirow{3}{*}{$\mathrm{ABCG}$} & Phase A & 10095 & 0.4472 & 14390 & 1.5279 & $3.2721 \mathrm{e}-04$ & $7.1279 \mathrm{e}-05$ & $5.3657 e-04$ & $2.7708 \mathrm{e}-04$ & 24487 & \multirow{3}{*}{71302} \\
\hline & Phase B & 6400.9 & 0.7334 & 7942.1 & 1.7080 & $7.6967 e-04$ & $1.7628 \mathrm{c}-04$ & 0.0013 & $6.6685 \mathrm{e}-04$ & 14346 & \\
\hline & Phase C & 12804 & 0.1193 & 19664 & 0.6083 & $1.2920 \mathrm{e}-04$ & $3.0109 \mathrm{e}-05$ & $2.1862 e-04$ & $1.1299 e-04$ & 32469 & \\
\hline
\end{tabular}


Table 3. (Entropy values at node 3 for with load)

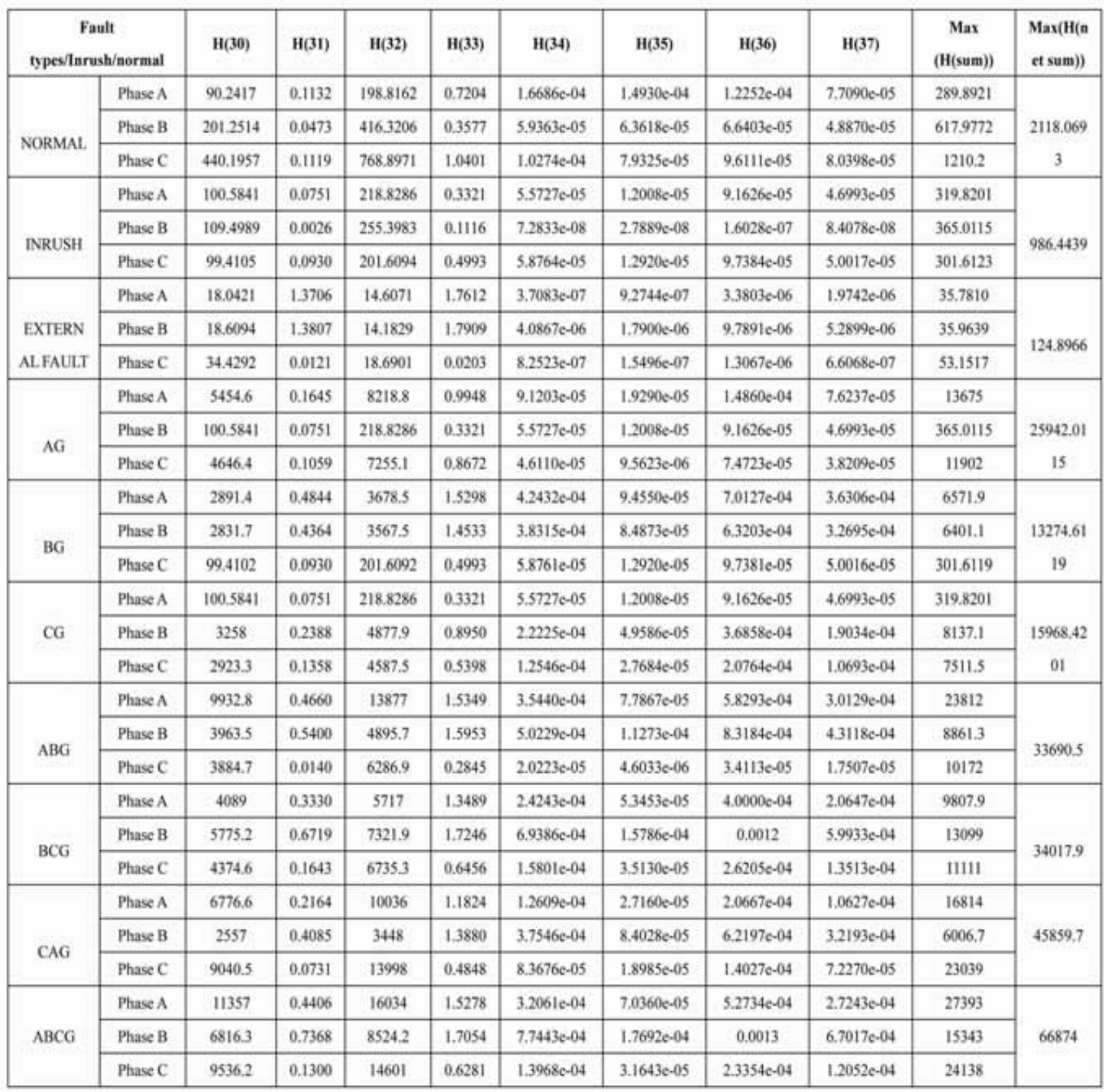

Table 4. Classification Rate

\begin{tabular}{|c|c|c|c|c|}
\hline Condition & $\begin{array}{c}\text { No Of } \\
\text { Patterns }\end{array}$ & $\begin{array}{c}\text { Correct } \\
\text { Patterns }\end{array}$ & Incorrect Patterns & Classification Rate \\
\hline Testing & 132 & 131 & 1 & 99.24 \\
\hline Training & 132 & 132 & Nil & 100 \\
\hline
\end{tabular}

Total Patterns used for training \& testing is $=264$

Training=132 patters; Testing $=132$ patterns

$\%$ Classification rate $=100 *$ (Total patterns-Incorrect patterns $) /($ Total patterns $)$

$\%$ Testing classification rate $=100 *(264-1) / 264=99.24$ 


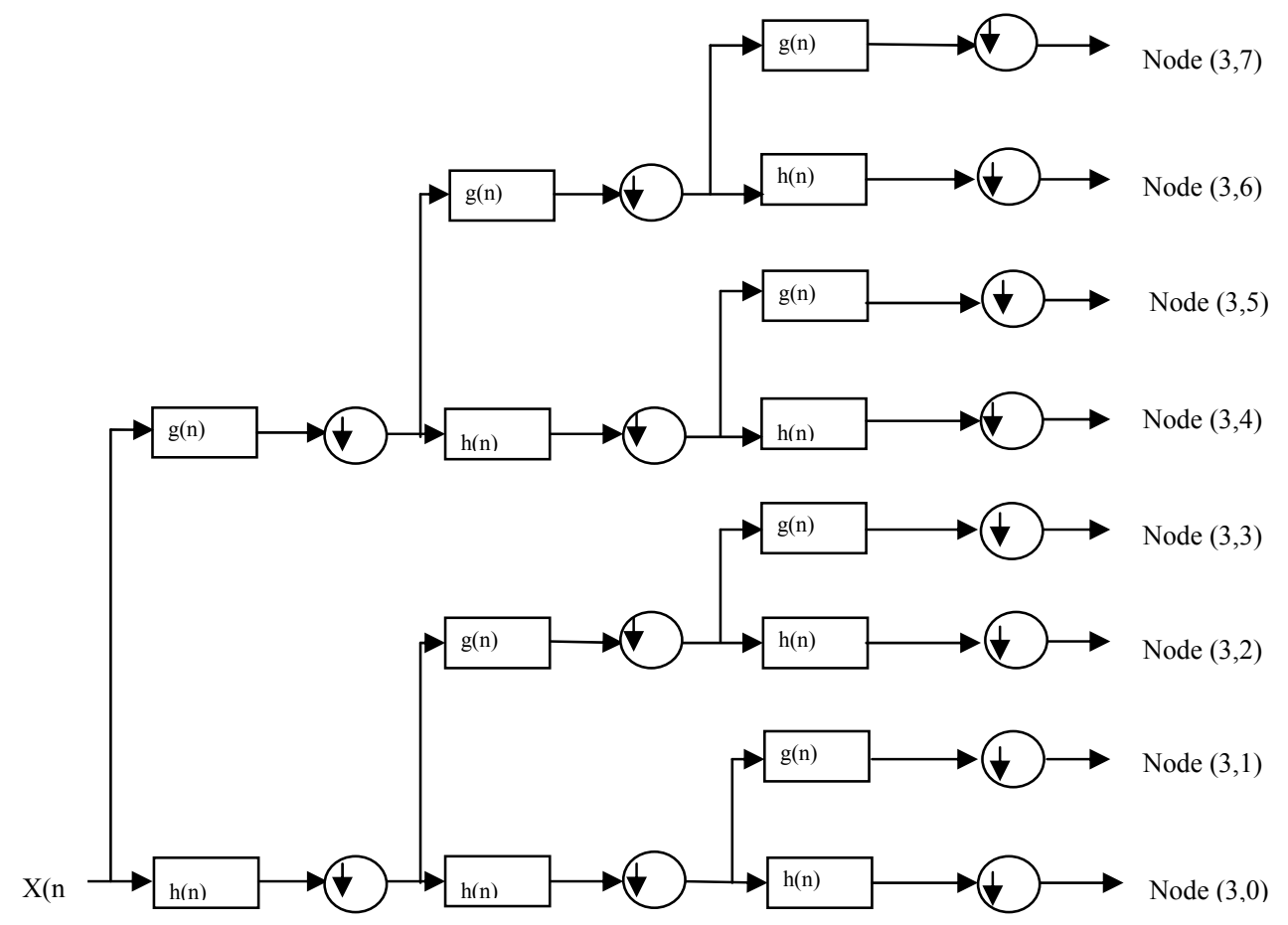

Figure 1. Wavelet Packet Tree

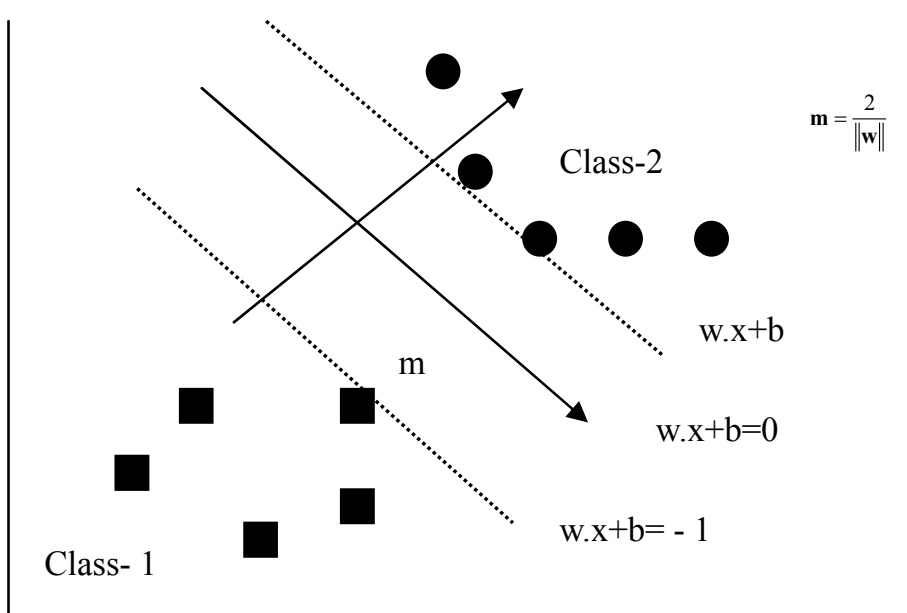

Figure 2. Optimal Separating Plane 


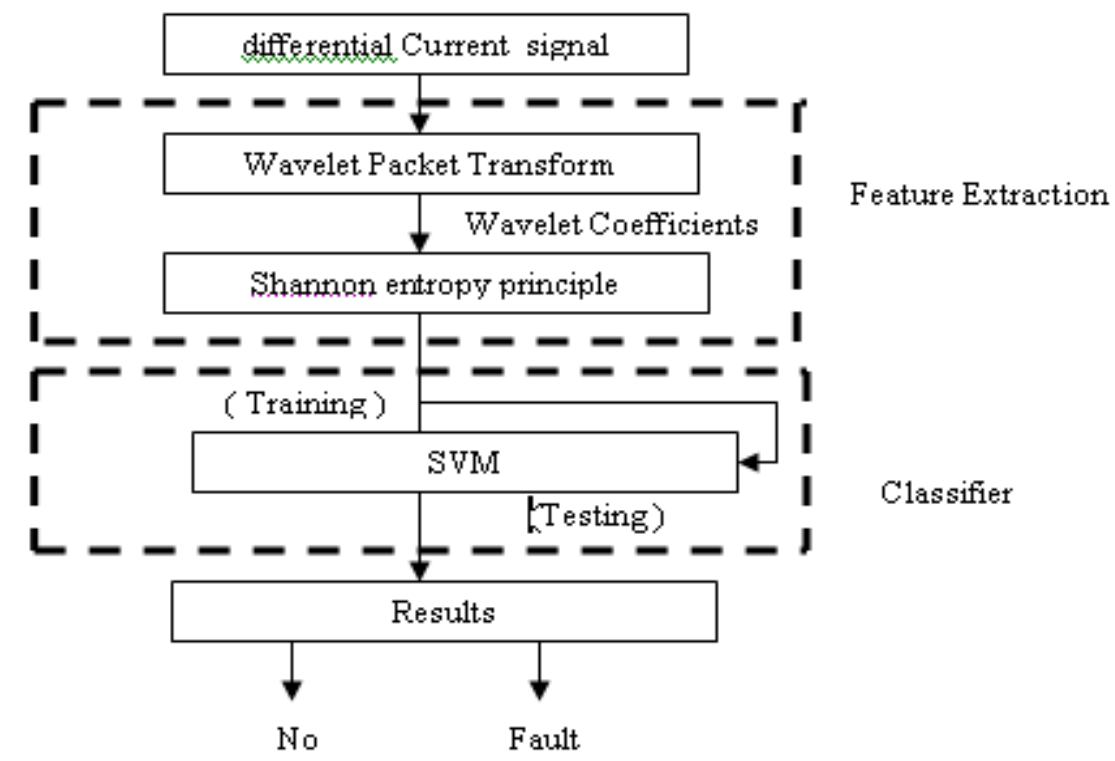

Figure 3. Algorithm for Relay Operation using Wavelet Packet Transform

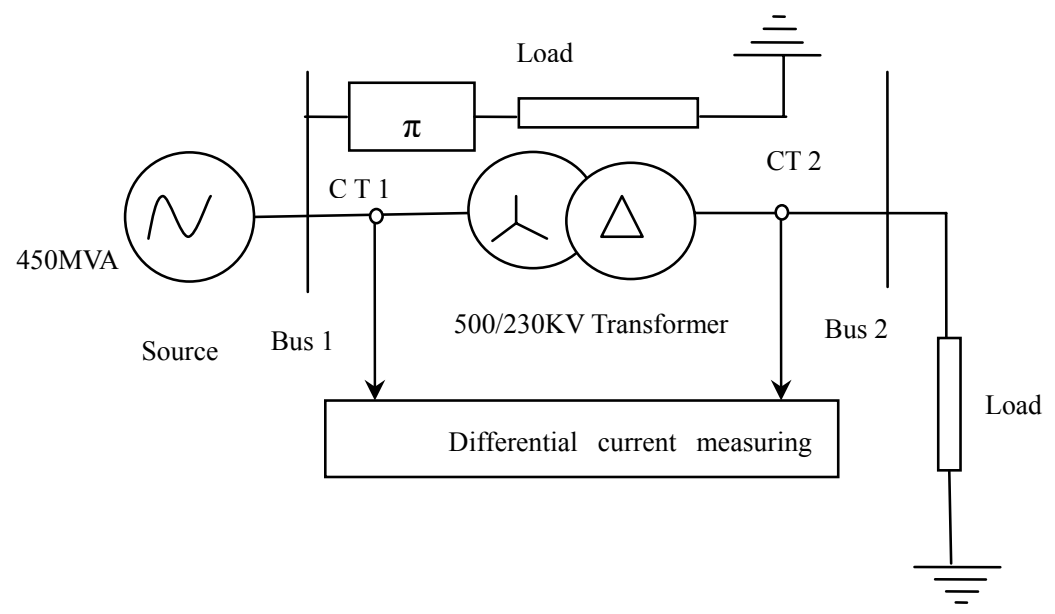

Figure 4. Power system Model
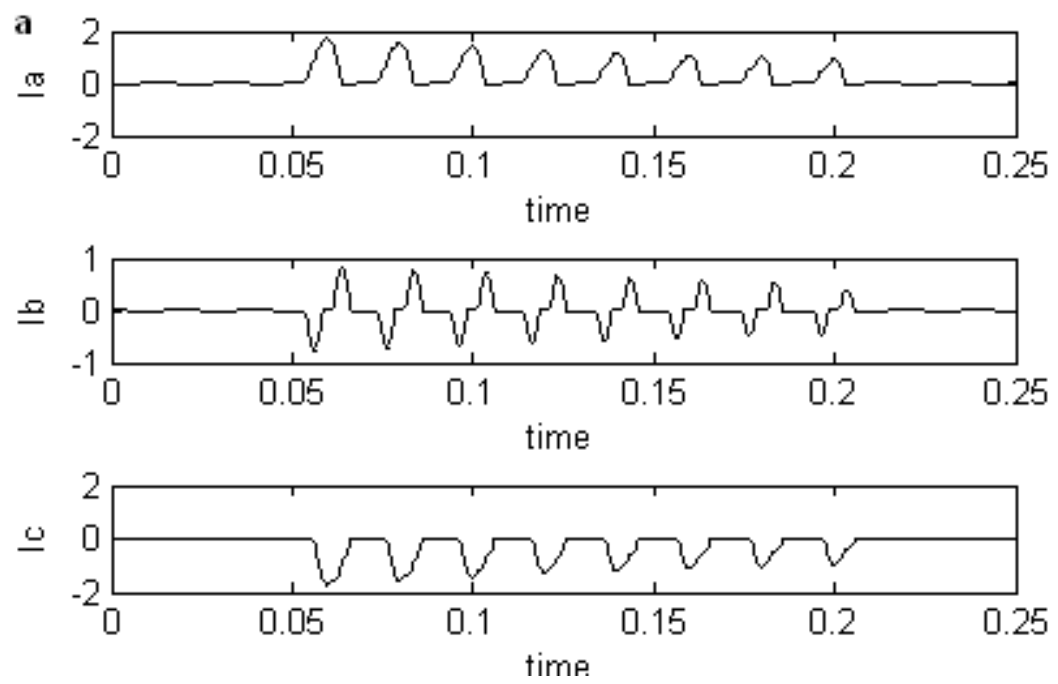

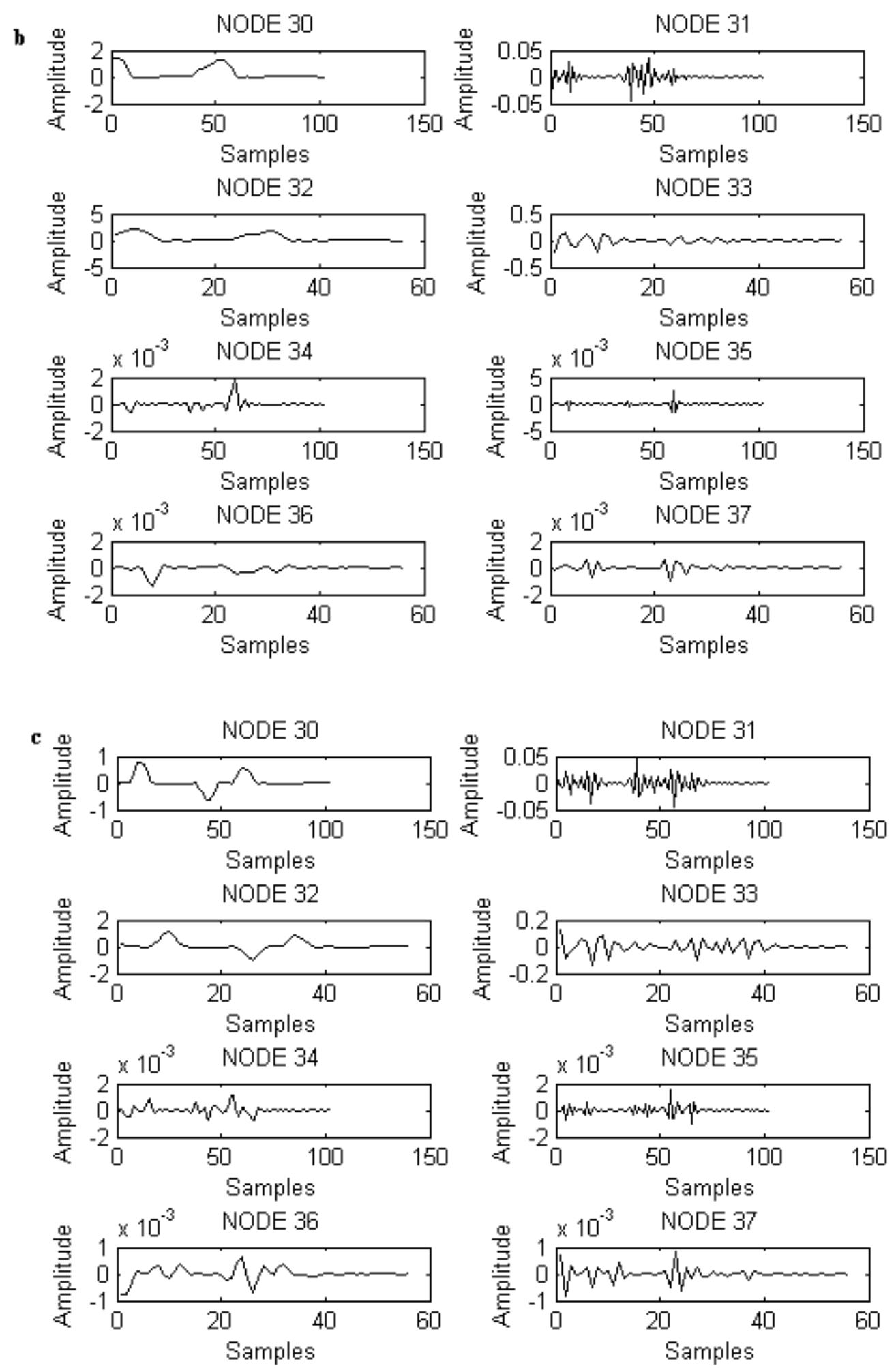

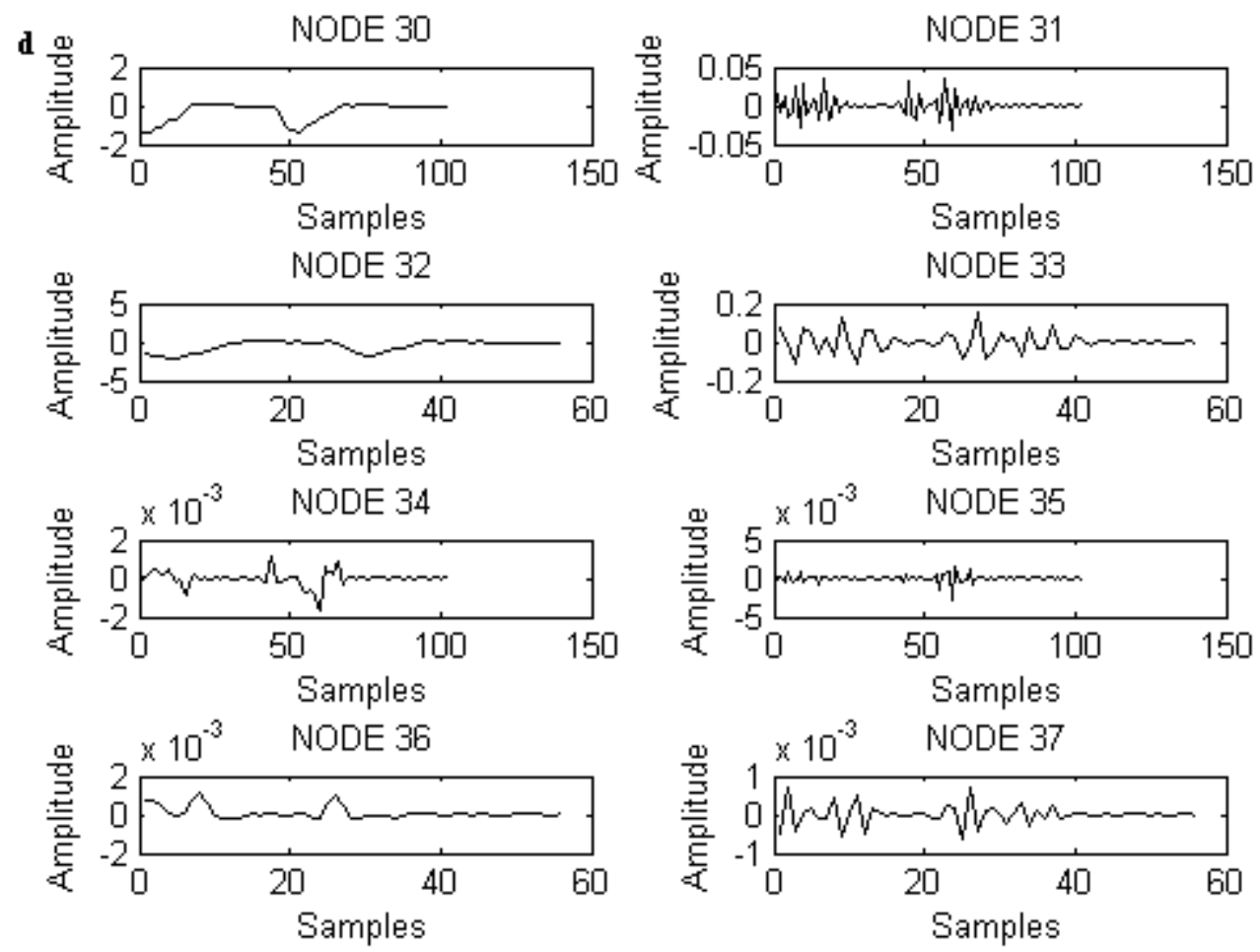

Figure 5. a) Differential current for three phase inrush current

b) Differential current of Phase a at node 3,7

c) Differential current of Phase $b$ at node 3,7

d)Differential current of Phase c at node 3,7
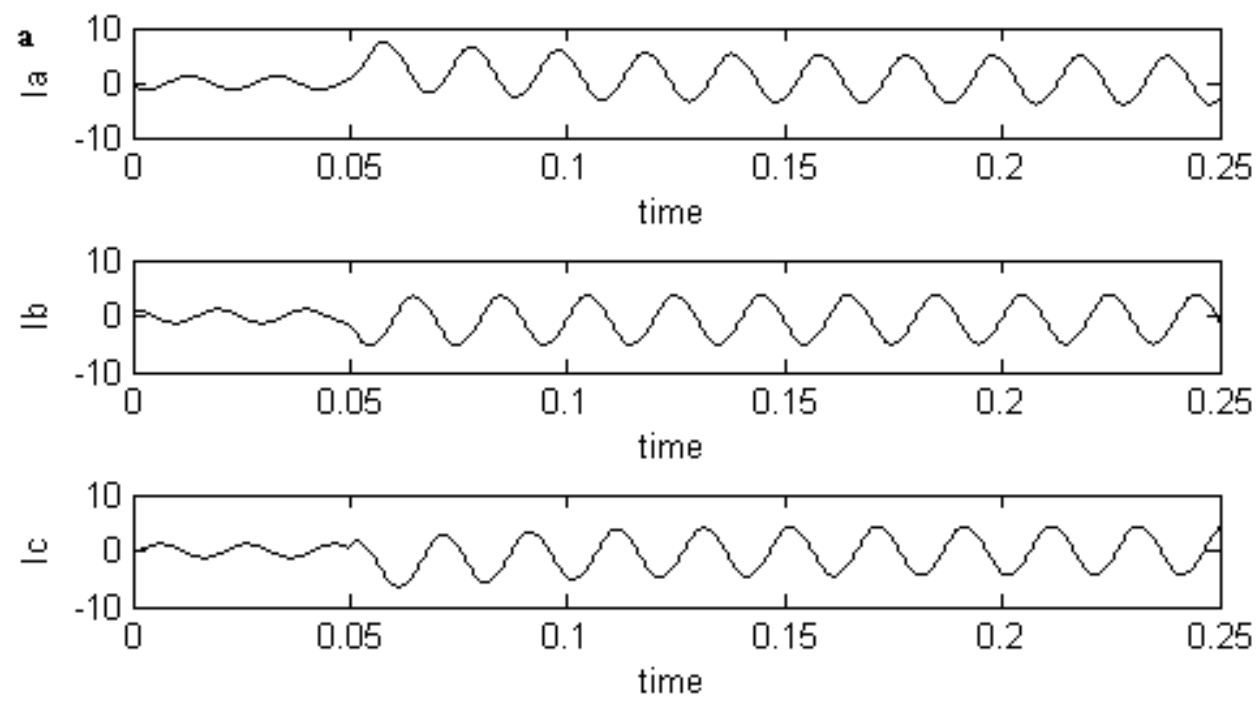

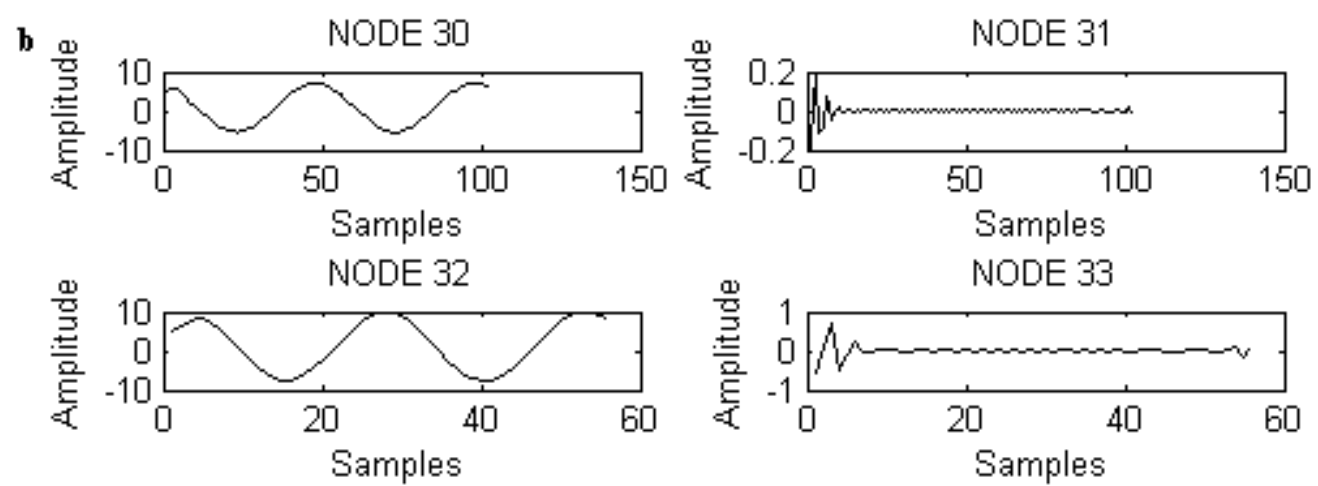

WODE 3.3
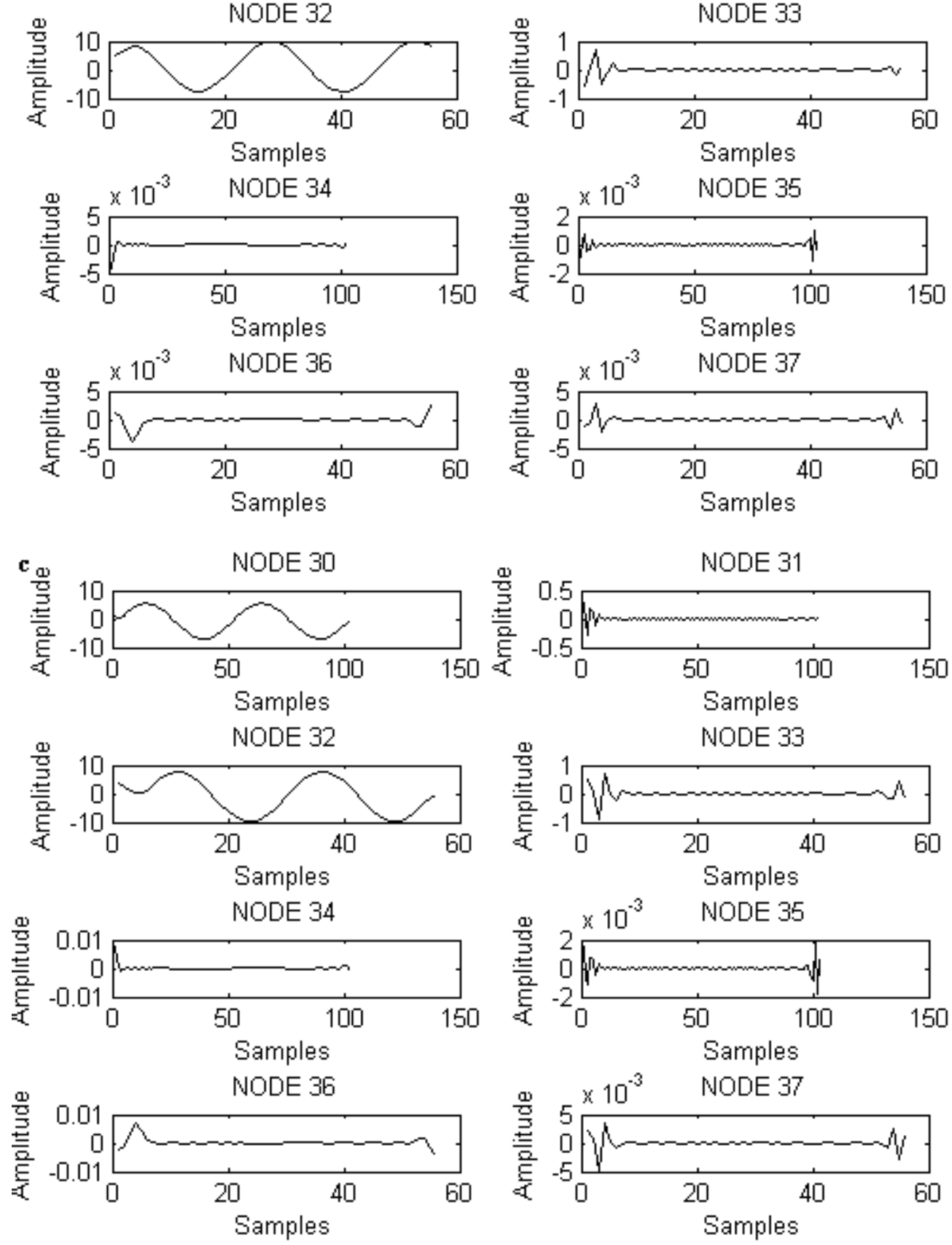

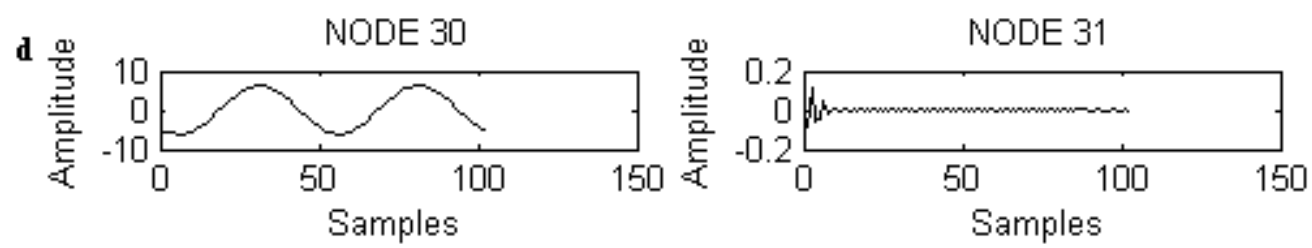

NODE 32
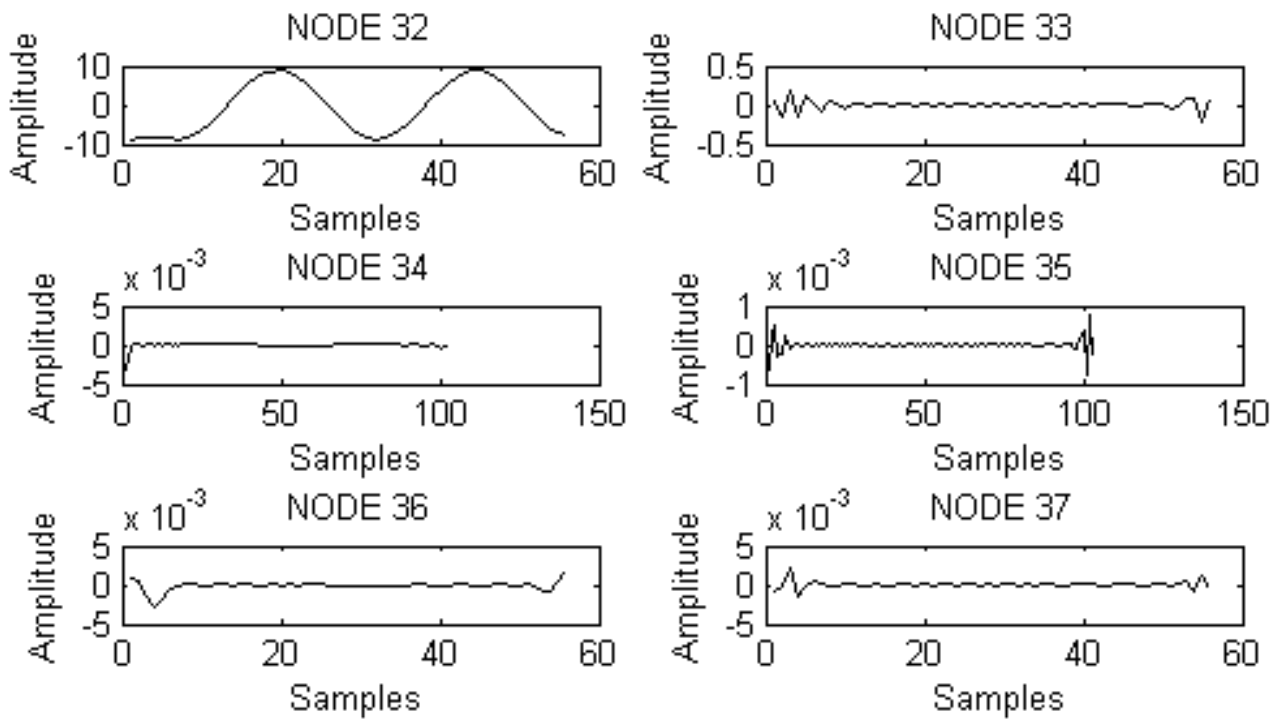

Figure 6. a) Differential current for three phase fault current

b) Differential current of Phase a at node 3,7

c) Differential current of Phase $b$ at node 3,7

d)Differential current of Phase $\mathrm{c}$ at node 3,7

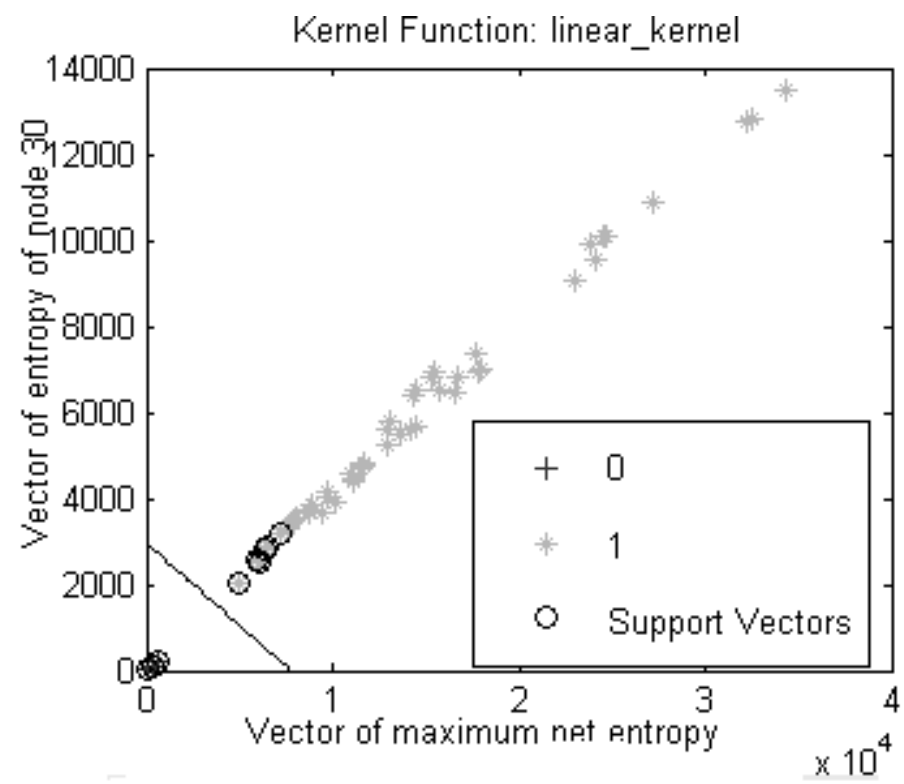

Figure 7. Trained Vectors Using SVM 


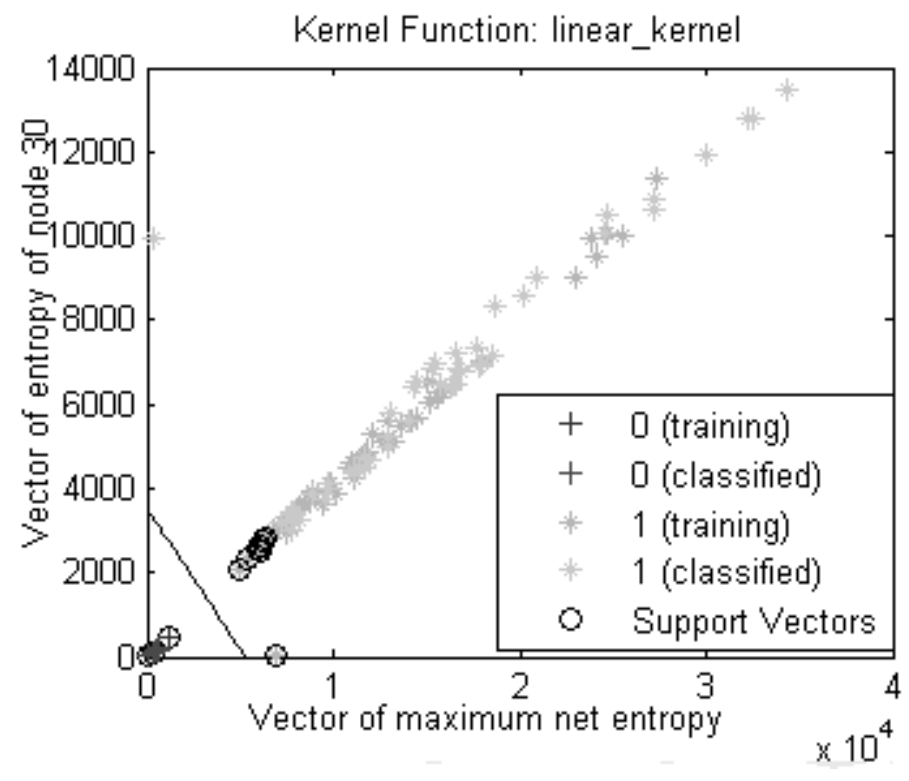

Figure 8. Tested Vectors Using SVM 